\title{
Influence of the near standing hall for wind flowing around group of circular cylinders
}

\author{
Ivana Veghova ${ }^{1, *}$ and Olga Hubova ${ }^{1}$ \\ ${ }^{1}$ Slovak University of Technology, Faculty of Civil Engineering, Department of Structural \\ Mechanics, Radlinskeho 11, Bratislava 810 05, Slovakia
}

\begin{abstract}
This article deals with experimental investigation of air flow around in - line standing circular cylinders and influence of nearby standing hall on external wind pressure distribution. The wind pressure distribution on the structures is an important parameter in terms of wind load calculation. For vertical circular cylinders in a row arrangement only wind force coefficient is possible find in Eurocode. 1991-1-4. External wind pressure coefficient depends on wind direction and the ratio of distance and diameter $b$. Influence of nearby standing structure is not possible find in Eurocode. The series of parametric wind tunnel studies was carried out in Boundary Layer Wind Tunnel (BLWT) STU to investigate the external wind pressure coefficient in turbulent wind flow. Experimental measurements were performed in BLWT for 2 reference wind speeds, which fulfilled flow similarity of prototype and model. We have compared the results of free in - line standing 3 circular cylinder and influence of hall on distribution of wind pressure at 3 height levels in turbulent wind flow and these results were compared with values in EN 1991-1-4.
\end{abstract}

\section{Introduction}

In the aerodynamics of structures it is necessary to determine the wind load, which is represented by a simplified set of pressures or forces for the whole structure, or for the structural parts.

The recent years were accompanied by the rise of the wind storms and height of wind velocity. Circular cylinders for example tanks, light masts, chimneys, towers, cables, open frames and structural elements or open lattice structures with circular cross section are frequently used in civil engineering structures. Characteristics of wind pressures and wind pressure coefficients were investigated recently by many authors - Strouhal, Kármán, Scruton, Davenport, Cermak, Solari [1] and others [2]. Some wind effects, especially interference effects and influences of near standing structures are still the subject of research and experimental measurements in wind tunnels, but also in-situ.

The parametric wind tunel studies was made in BLWT to investigate the effects of distance and roughness of cylinders in steady wind flow. In terrain category I and II, with

\footnotetext{
*Corresponding author: ivana.veghova@stuba.sk
} 
turbulence intensity below $10 \%$, have reached suction coefficient $\mathbf{c}_{\mathbf{p e}}=\mathbf{- 3 . 1 2} \div \mathbf{- 3 . 7 2}$ for Reynolds number: $2.27 \cdot 10^{5}-2.55 \cdot 10^{5}$. In the case of a rough surface, the suction values were $\mathbf{c}_{\text {pe }}=\mathbf{- 2 . 2 6} \div \mathbf{- 2 . 8 1}$ see results [3].

\section{Turbulent wind flow in BLWT}

The basic characteristics of turbulent wind flow are as follows:

The wind velocity at the height $\mathrm{z}$ and time $\mathrm{t}$ can be expressed:

$$
V(z, t)=v_{m}(z)+v(z, t)
$$

where

$$
v_{m}(z, t)=\frac{1}{T} \int_{0}^{T} v(z, t) d t=v_{m}(z)
$$

is mean wind velocity at height $z, v(z, t)$ is fluctuating part of wind.

Turbulence intensity at height $z$ is defined as the standard deviation divided by mean velocity:

$$
I_{v}(z)=\frac{\sigma_{v}(z)}{v_{m}(z)}=\frac{k_{I}}{c_{o}(z) \cdot \ln \left(z / z_{0}\right)}=\frac{1}{c_{o}(z) \cdot \ln \left(z / z_{0}\right)}
$$

where $\mathrm{z}_{0}$ is roughness length.

Power spectral density function - wind distribution over frequencies:

$$
\int_{0}^{\infty} S_{v}(z, n) d n=\sigma_{v}^{2}
$$

The wind velocities distribution measured in the boundary layer wind tunnel for different height levels is depicted in Fig.1.

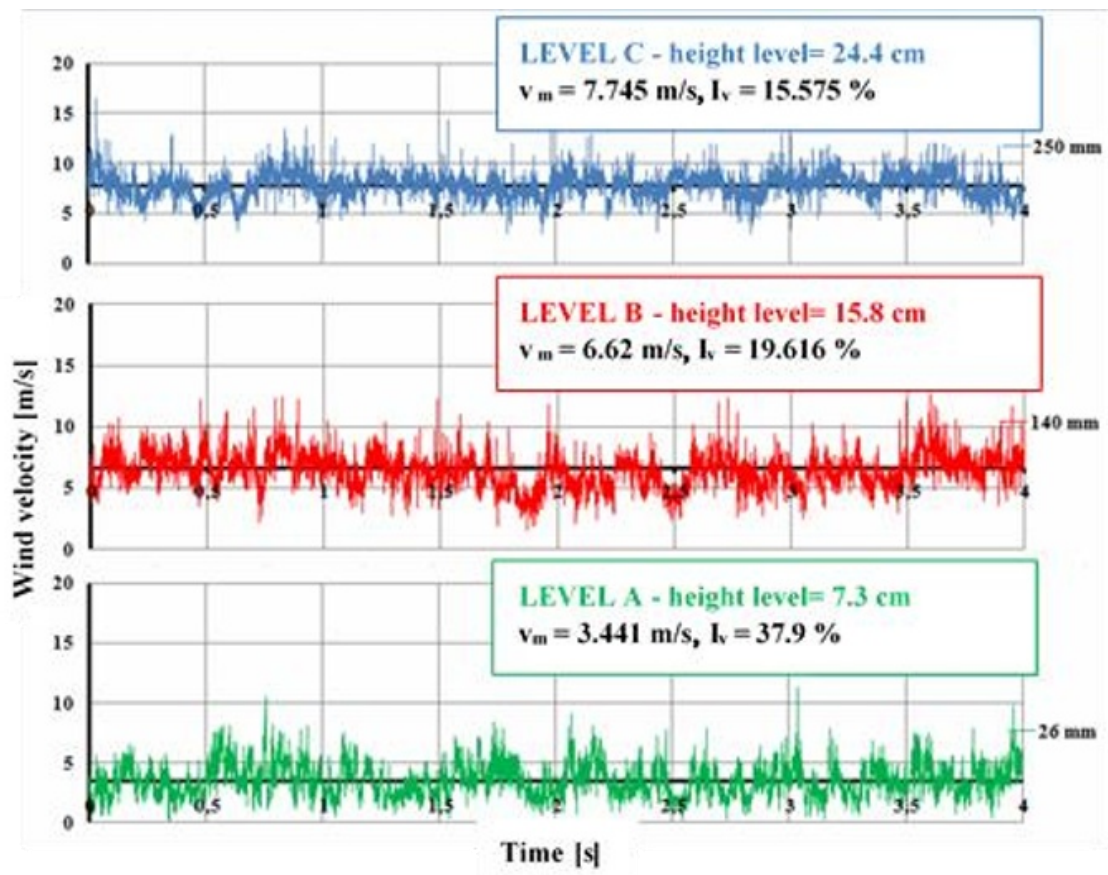

Fig. 1. Measured turbulent wind velocity in ROS of BLWT in three levels - A, B, C. 


\section{Experimental investigations of coupled circular cylinders}

In the BLWT wind tunnel in Bratislava (see Fig. 2.), we tested according to [4] in the rear measuring space cylinders at different wind speeds and configuration.
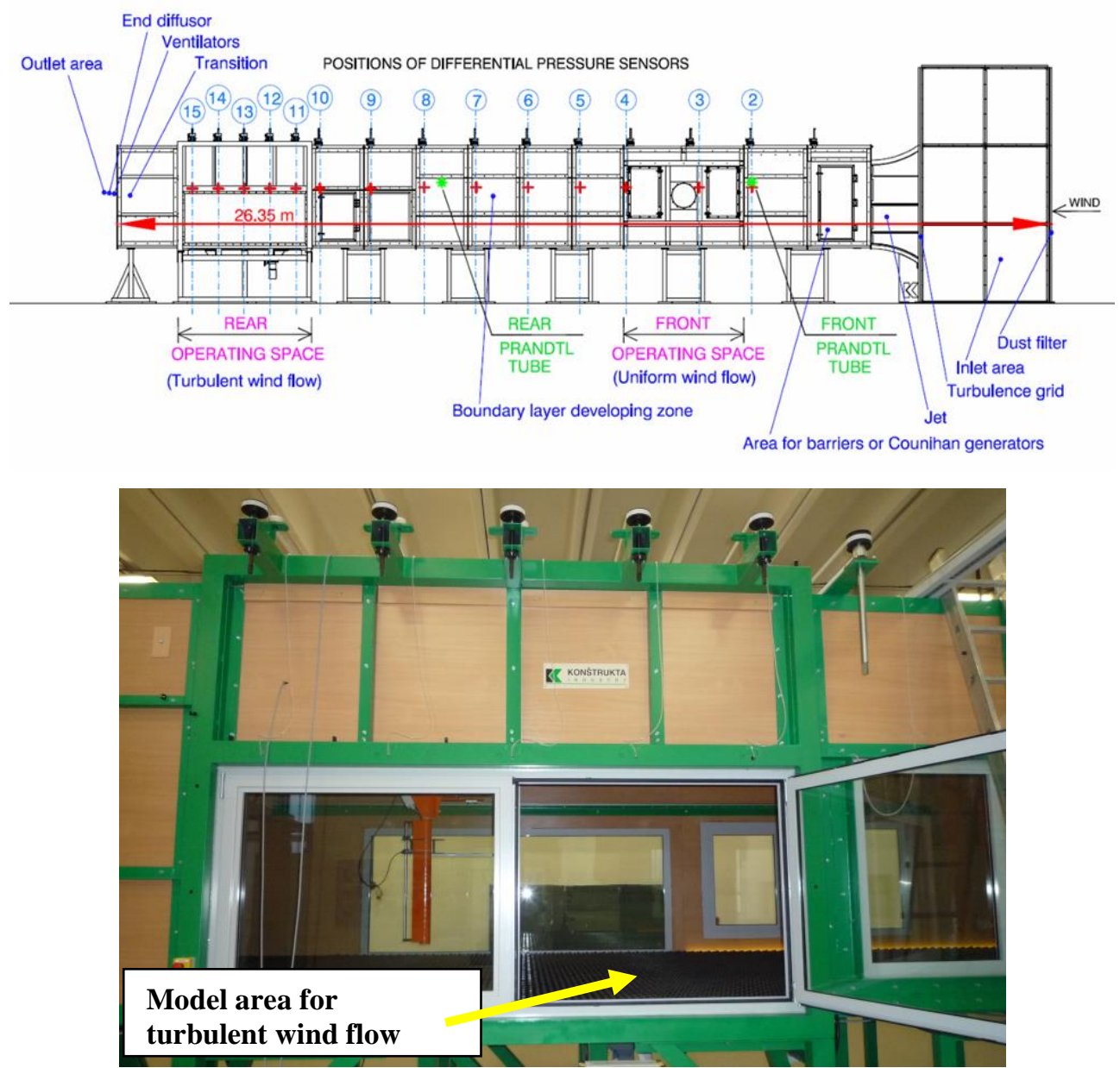

Fig. 2. BLWT wind tunnel scheme and view of the rear test.

Position of sampling points and wind direction $0^{\circ}$ was considered perpendicular to the longitudinal axis of the cylinder.

Wind pressure and pressure coefficients in turbulent flow depend upon the Reynolds number and equivalent roughness:

$$
R e=\frac{b \cdot v}{v}
$$

where: $\quad \mathrm{b}$ is the diameter, $v$ is the kinematic viscosity of air $\left(v=1.5 \cdot 10^{-5} \mathrm{~m}^{2} / \mathrm{s}\right)$.

To verify the numerical solutions, it is necessary to obtain the values of wind pressure and velocity by other methods. Conducting experimental measurements, either in wind tunnels or directly by measuring in situ using real structures, is the best method to verify them. Extensive experiments were carried out for stand-alone cylinders and wind pressure distribution for different Reynolds number values can be found in the standard [5]. The figure 3 shows the external wind pressure coefficient at the periphery of the cylinder. 

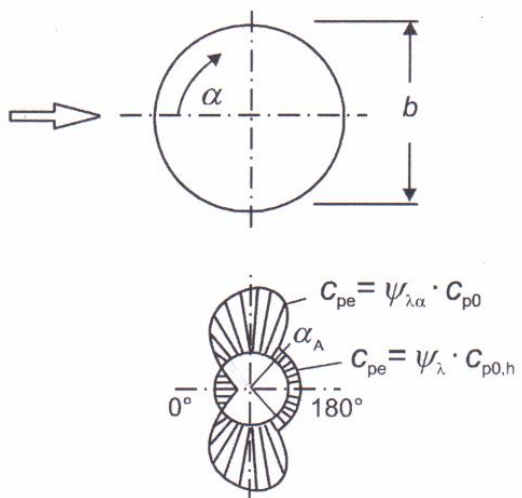

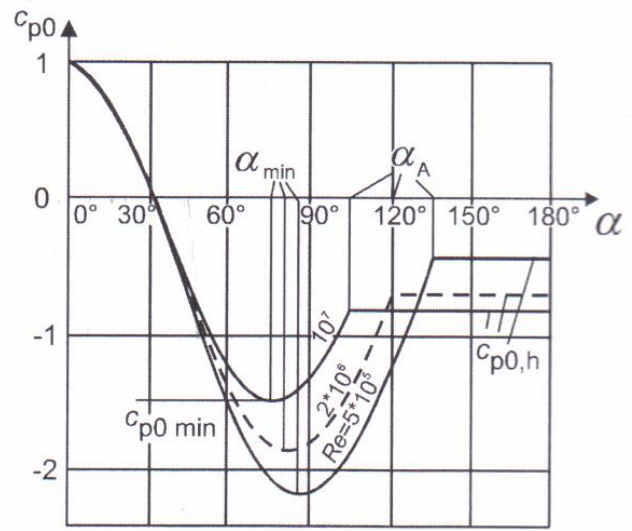

Fig. 3. Distribution of external wind pressure coefficient for circular cylinders for different Re [5].

Our task was to determine the effect of near-standing cylinders and buildings on the distribution of wind pressure. Fig. 4 shows a view of three standing cylinders during experimental measurements in a wind tunnel. The cylinder with dark dome was measured at 3 height levels - A,B,C.

Experimental measurements of external coefficients were determined at 3 reference wind speeds, their values and Reynolds numbers are shown in Table 1.

Table 1.

\begin{tabular}{|c|c|c|}
\hline $\begin{array}{c}\text { Frequency of } \\
\text { converters }[\mathbf{H z}]\end{array}$ & $\begin{array}{c}\text { Speed reference Vref }[\mathbf{m} / \mathbf{s}], \\
\text { height level } 27 \mathbf{~ c m}\end{array}$ & Reynolds number Re \\
\hline 20 & 8.4348 & $0.90 \cdot 10^{5}$ \\
\hline 24 & 10.541 & $1.12 \cdot 10^{5}$ \\
\hline 28 & 12.7485 & $1.35 \cdot 10^{5}$ \\
\hline
\end{tabular}

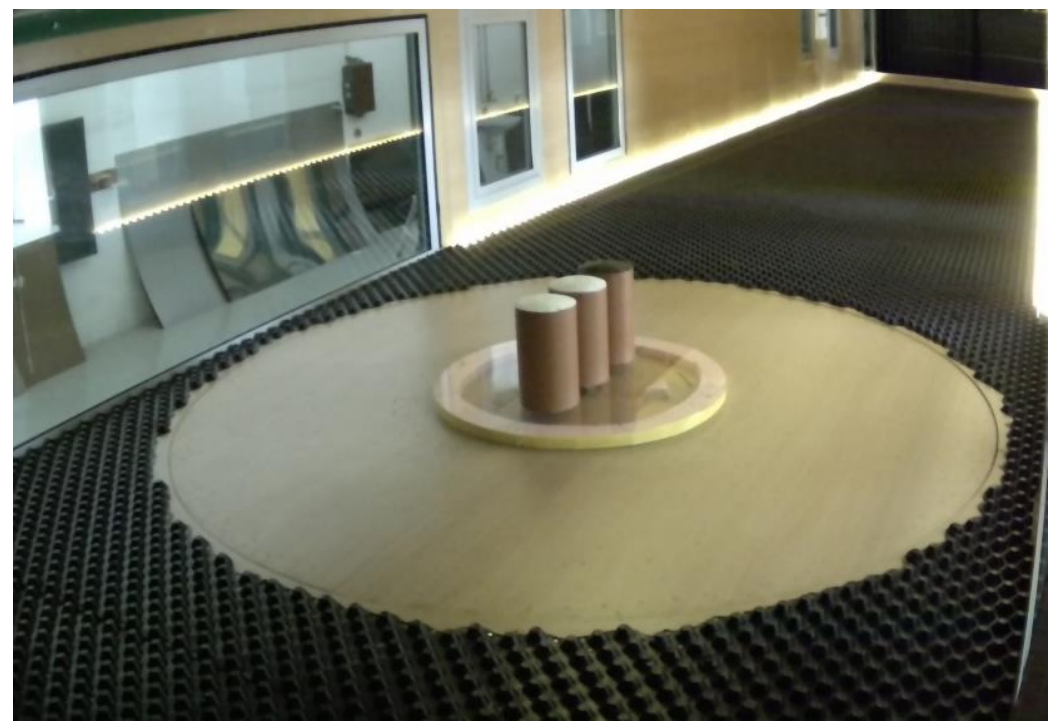

Fig. 4. View of the cylinders in the rear measuring space in turbulent flow. The side cylinder with dark dome was measured. 
Measurements were performed on smooth cylinders where the height of the model was $\mathrm{h}=0.26 \mathrm{~m}$, diameter $\mathrm{b}=0.16 \mathrm{~m}$ and distance between cylinders was $\mathrm{d}=0.033 \mathrm{~m}$. The wind pressure on the side cylinder as well as the cylinder located in the center was monitored see Figs. 4 and 6.

Position of the sampling points $1-32$ at different levels and wind directions is visible in Fig. 5. The wind direction has changed by $15^{\circ}$. Results of the experimental measurements - mean value of external wind pressure coefficients for the largest suction on near-standing cylinders is shown in Figs. 5 and 7.

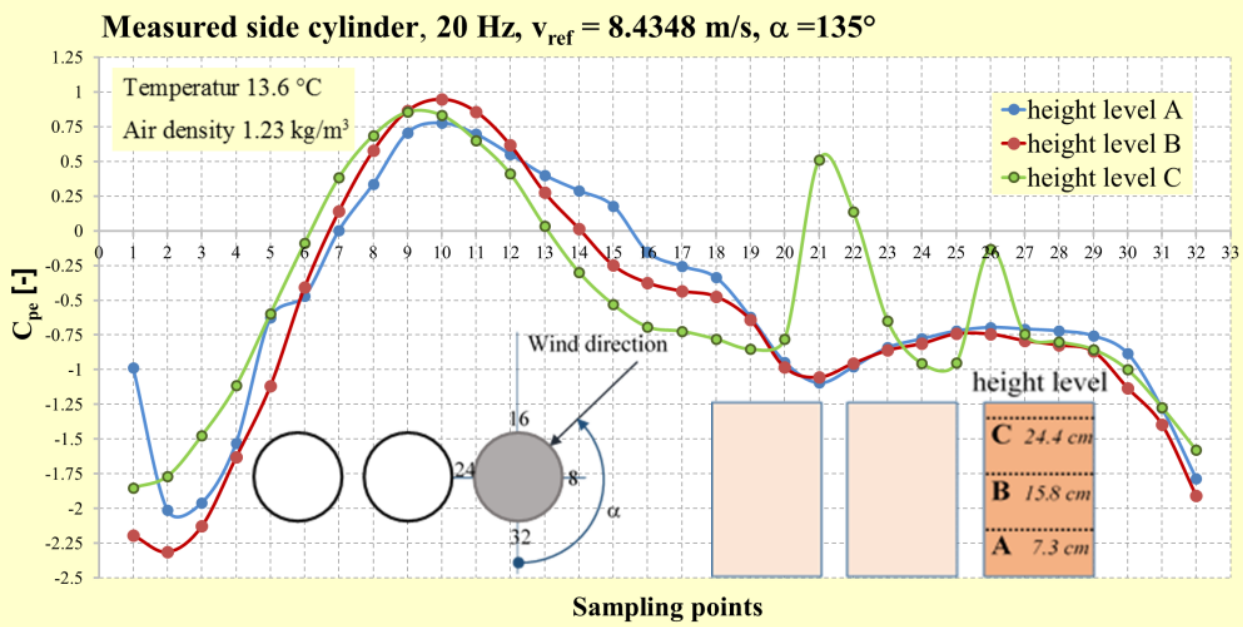

Fig. 5. External wind pressure coefficient in turbulent wind flow, wind direction $135^{\circ}$.

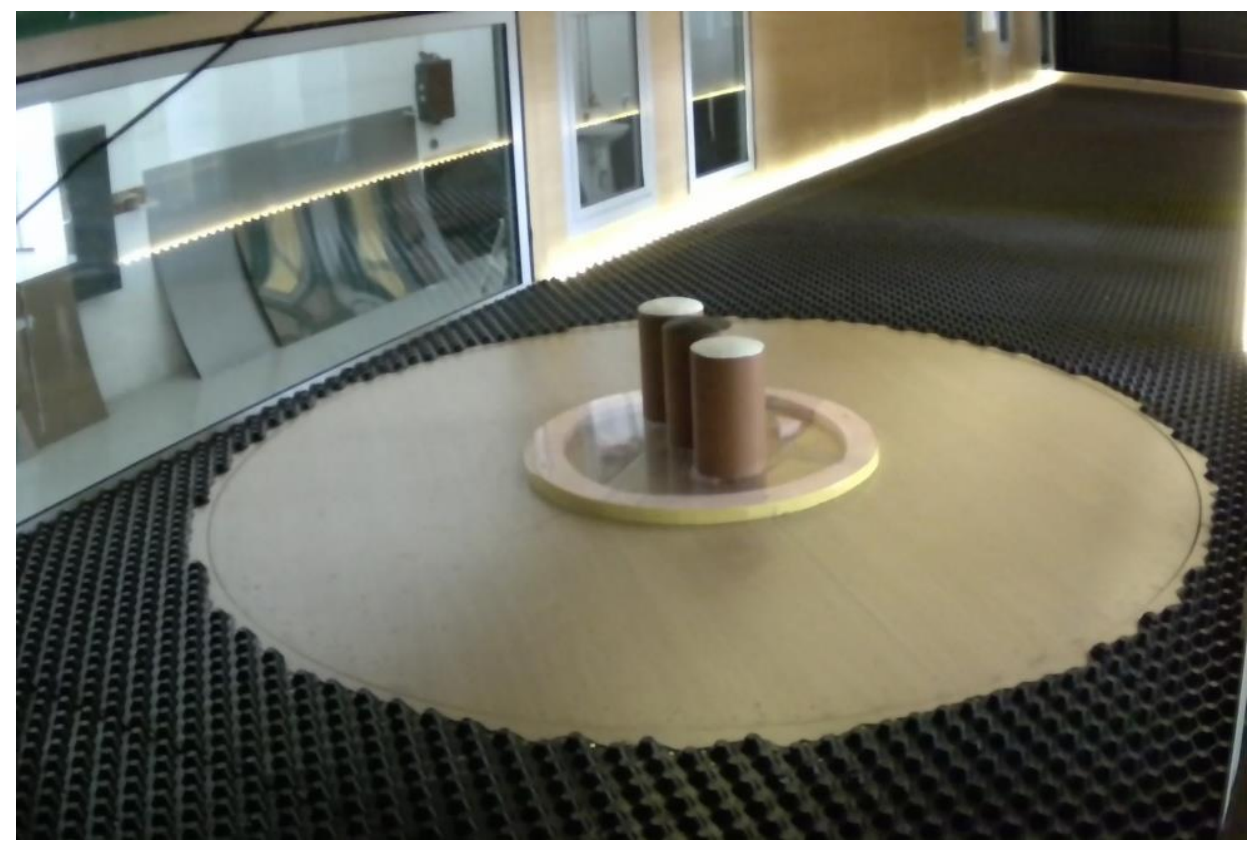

Fig. 6. View of the cylinders in the rear measuring space in turbulent flow. 


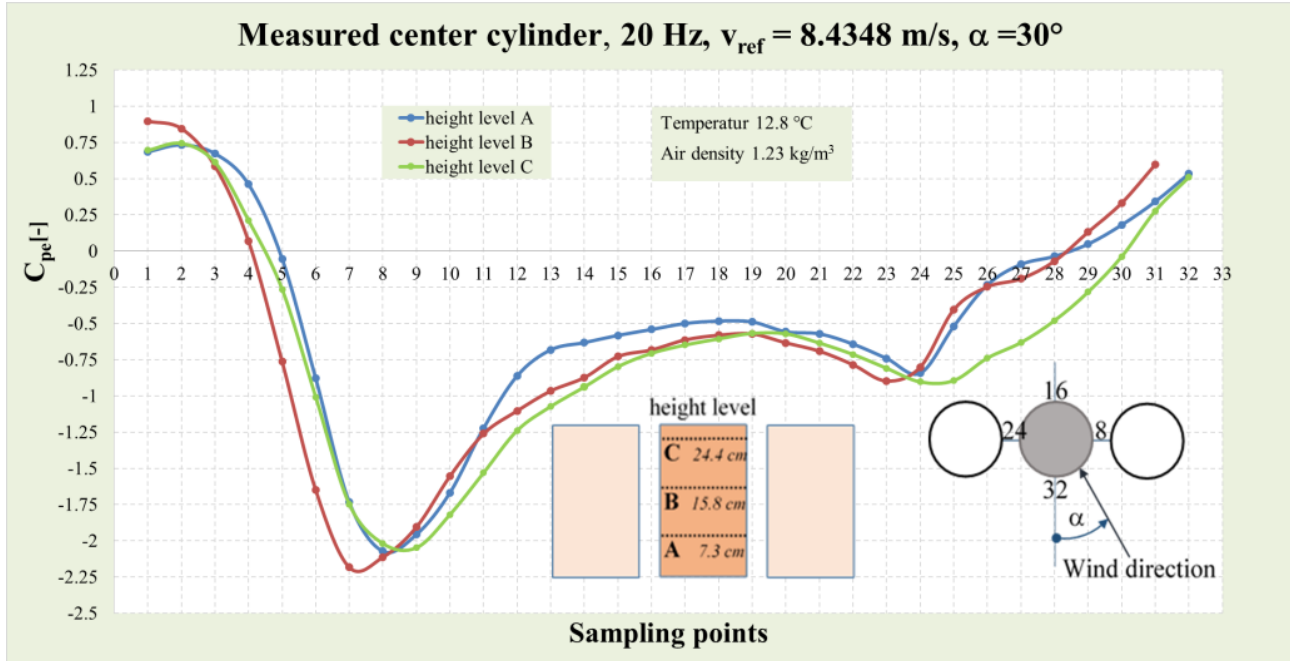

Fig. 7. External wind pressure coefficient in turbulent wind flow, wind direction $30^{\circ}$.

Experimental measurements continued by observing the effect of the near-standing hall and tested the distribution of wind pressures on the side cylinder as well as the center cylinder. We monitored the real disposition of objects in the area of nuclear power plant.

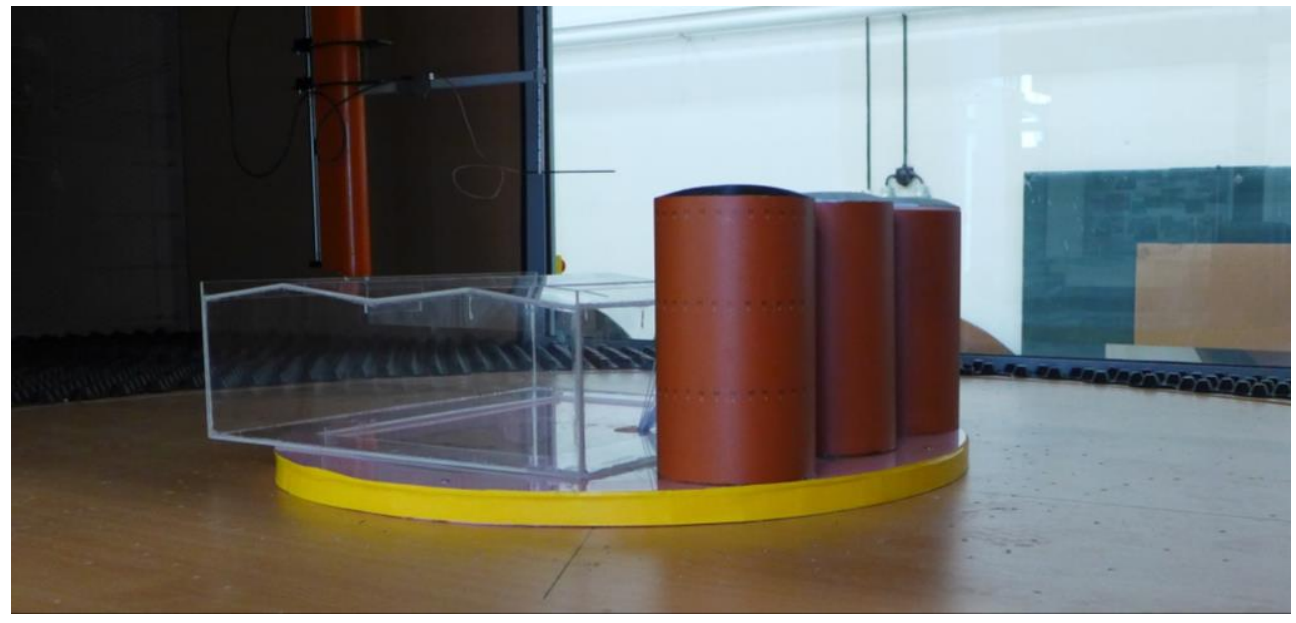

Fig. 8. View of the cylinders with hall in the rear measuring space in turbulent flow.

The most unfavorable suction values for the side and middle cylinder as well as the distribution of the mean value of the external wind pressure coefficient are shown in Figs. 9 and 11 . 


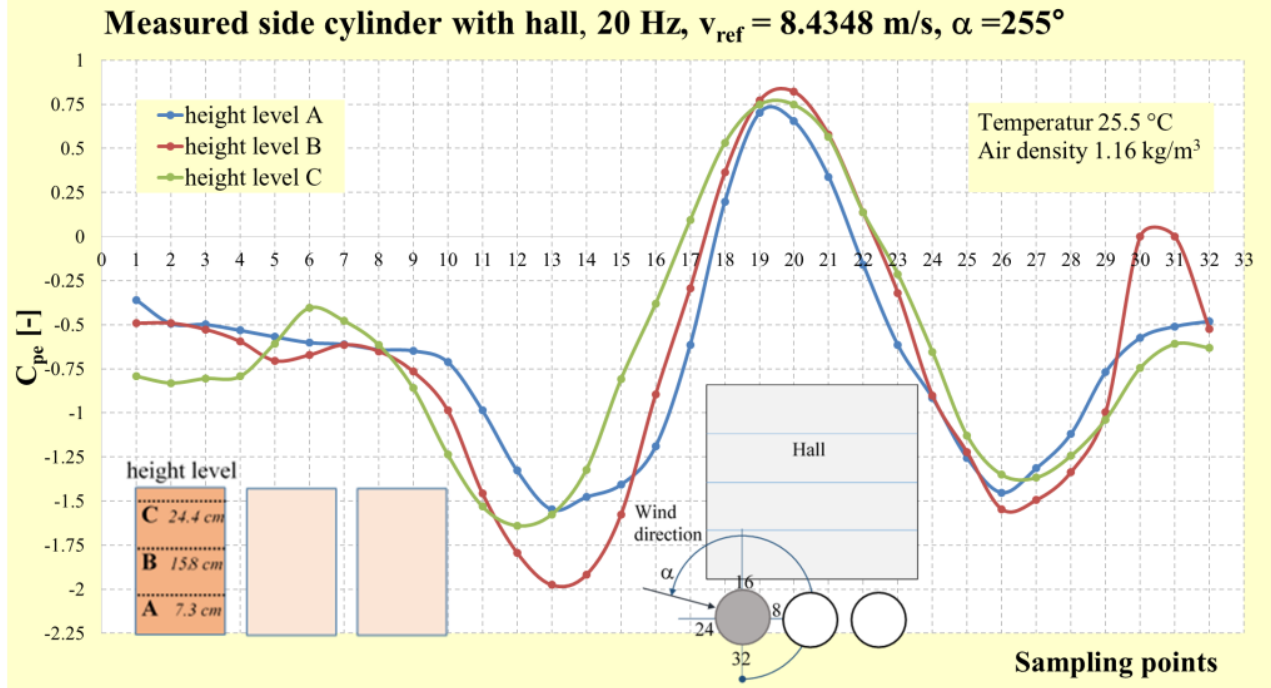

Fig. 9. External wind pressure coefficient in turbulent wind flow, wind direction $255^{\circ}$.

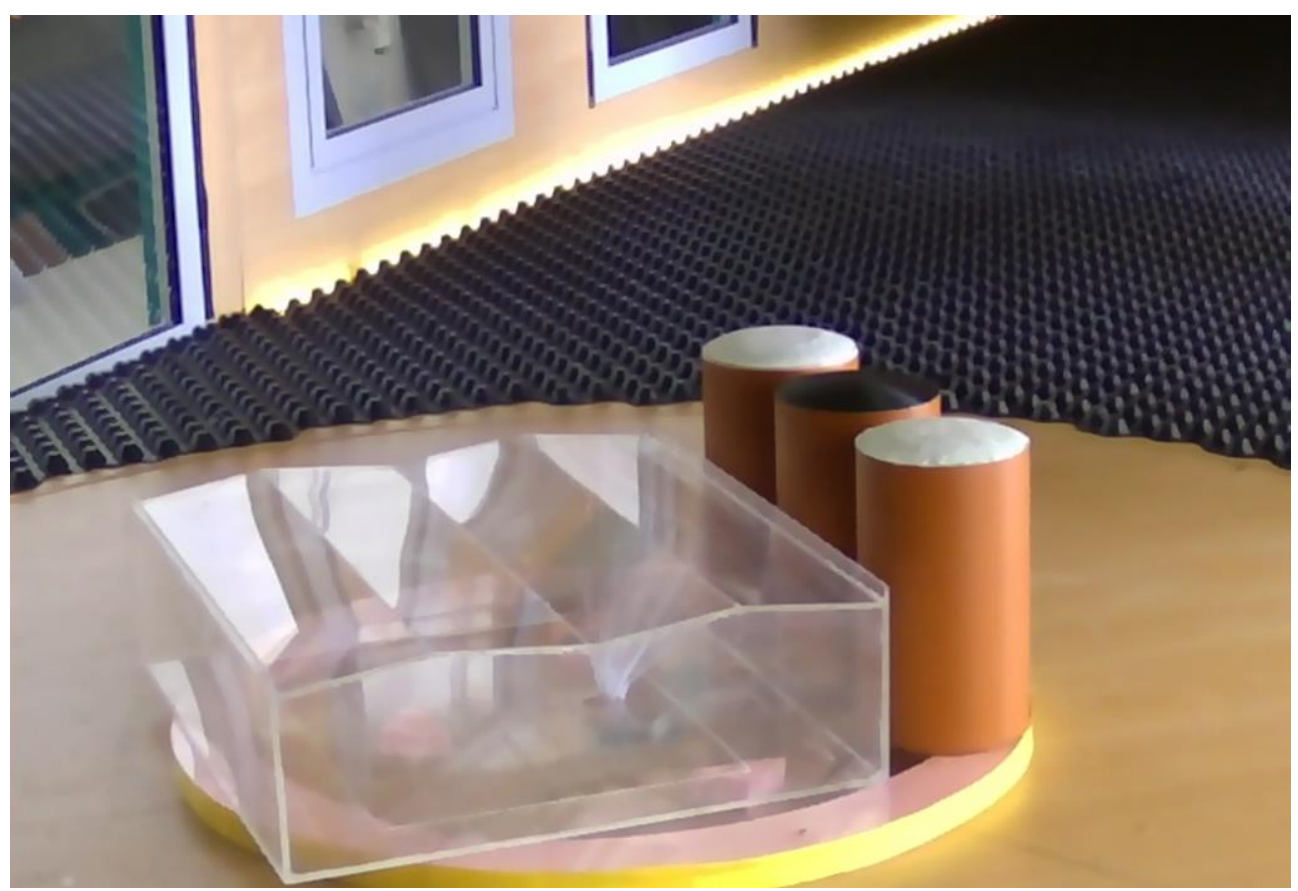

Fig. 10. View of the cylinders with hall in the rear measuring space in turbulent flow.

Significant influence on the distribution of external wind pressure has a rear-standing hall in the case of monitoring the central cylinder. The absolute values of $c_{p e}$ are significantly lower than for the side cylinder, as shown in Fig. 11. In the case of the center placed cylinder, there is a significant difference of $c_{p e}$ between levels $\mathrm{A}, \mathrm{B}, \mathrm{C}$ and the influence of the free end is dominant. 


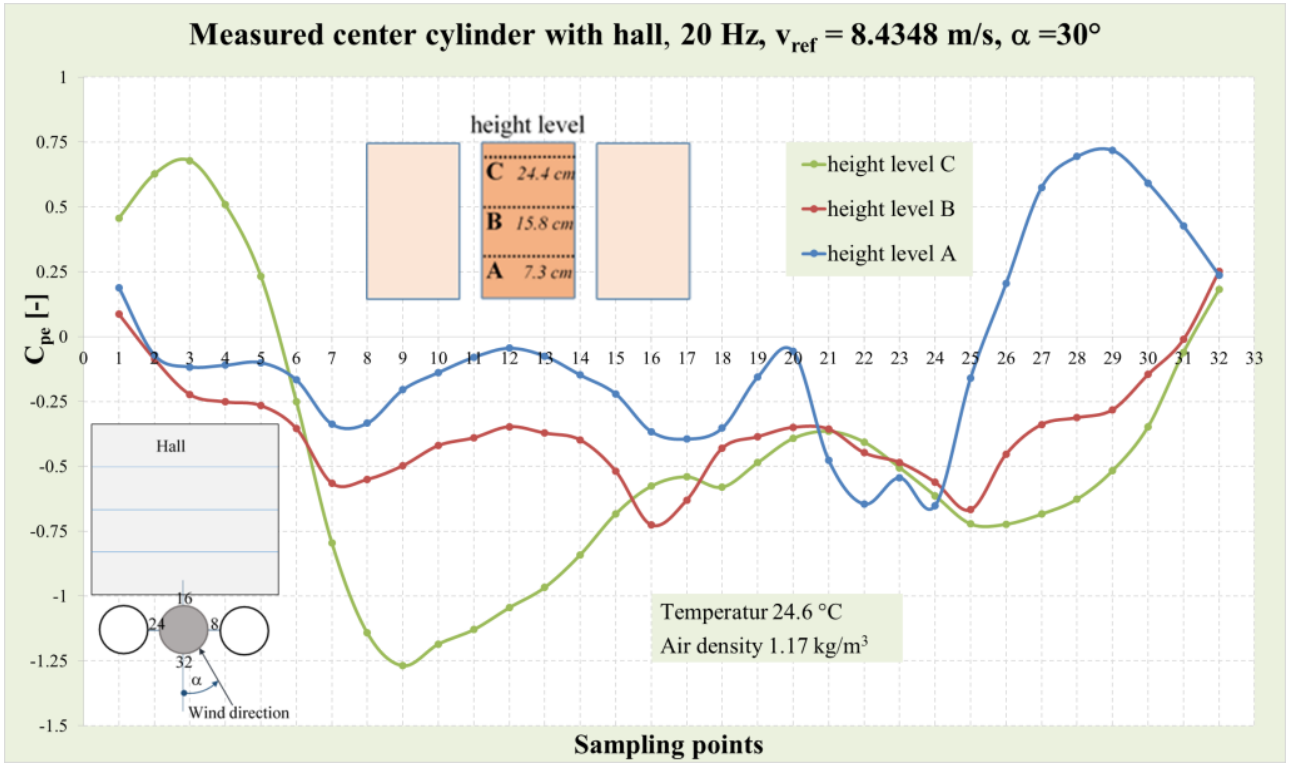

Fig. 11. External wind pressure coefficient in turbulent wind flow, wind direction $30^{\circ}$.

\section{Conclusions}

The values from the experimental measurements for smooth circular cylinders standing near each other in turbulent wind flow (near the ground in terrain category III-IV, with turbulence intensity below $37.5 \%$ ) have reached $\mathbf{c}_{\mathbf{p e}}=\mathbf{- 2 . 3 1}$ for side cylinder in level B and $\mathbf{c}_{\mathbf{p e}}=\mathbf{- 2 . 2}$ for the middle placed cylinder. External wind pressure coefficients were higher than EN standard value: $c_{p e}=-2.1$ for a single cylinder. At level $\mathrm{C}$ was seen significant influence of the free end of cylinder on side cylinder.

If a hall is located behind the row of cylinders, this affects the distribution of external wind pressures and reduces suction values for the side cylinder to -2 and for the cylinder placed in the middle the value $\mathrm{c}_{\mathrm{pe}}$ reaches only -1.25 .

In the case of in-line standing cylinders where the structures are exposed to the wind flow with higher speeds and lower turbulence, it is necessary to take into account the sidewalls stresses which can be different than the given one in EN standards.

Presented results have been arranged due to the research supported by the Slovak Scientific Grant Agency, project No. 1/0265/16 and project KEGA 025 STU-4/2019.

\section{References}

1. G. Solari, Gust buffeting. I, J. Struct. Engng., ASCE, 119,2 365-382, (1993)

2. P. Szczepaniak, A. Padewska, Applied Mechanics and Materials 769, 172-179, (2015)

3. O. Hubova, M. Franek, I. Veghova, CHMELIK, V. - RYCHTARIKOVA, M. ATF 2018, pp. 87--92 (2018)

4. ACSE Manuals and Reports on Engineering Practice, no.67. Wind Tunnel studies of buildings and structures Aerospace Division of the American Society of Civil Engineers (1999) 
5. EN 1991-1-4 Eurocode 1 (2006), Actions on structures, Part 1-4: General actions. Wind actions

6. O. Hubova, Slovak Journal of Civil Engineering 2007/3, XV (2007) 